\title{
Gene identification and transcriptome analysis of low cadmium accumulation rice mutant (Icd1) in response to cadmium stress using MutMap and RNA-seq
}

\author{
Zhen Zhen Cao*, Xiao Yan Lin, Yong Jie Yang, Mei Yan Guan, Ping Xu and Ming Xue Chen
}

\begin{abstract}
Background: Cadmium (Cd) is a widespread toxic heavy metal pollutant in agricultural soil, and $\mathrm{Cd}$ accumulation in rice grains is a major intake source of $\mathrm{Cd}$ for Asian populations that adversely affect human health. However, the molecular mechanism underlying $\mathrm{Cd}$ uptake, translocation and accumulation has not been fully understood in rice plants.

Results: In this study, a mutant displaying extremely low Cd accumulation (Icd1) in rice plant and grain was generated by EMS mutagenesis from indica rice cultivar 9311 seeds. The candidate SNPs associated with low Cd accumulation phenotype in the Icd 1 mutant were identified by MutMap and the transcriptome changes between Icd 1 and WT under $\mathrm{Cd}$ exposure were analyzed by RNA-seq. The Icd1 mutant had lower $\mathrm{Cd}$ uptake and accumulation in rice root and shoot, as well as less growth inhibition compared with WT in the presence of $5 \mu \mathrm{M} \mathrm{Cd}$. Genetic analysis showed that Icd1 was a single locus recessive mutation. The SNP responsible for low $\mathrm{Cd}$ accumulation in the Icd1 mutant located at position 8,887,787 on chromosome 7, corresponding to the seventh exon of OsNRAMP5. This SNP led to a Pro236Leu amino acid substitution in the highly conserved region of OsNRAMP5 in the Icd 1 mutant. A total of 1208 genes were differentially expressed between Icd 1 and WT roots under Cd exposure, and DEGs were enriched in transmembrane transport process GO term. Increased OsHMA3 expression probably adds to the effect of OsNRAMP5 mutation to account for the significant decreases in $\mathrm{Cd}$ accumulation in rice plant and grain of the $/ \mathrm{cd} 1$ mutant.

Conclusions: An extremely low Cd mutant Icd 1 was isolated and identified using MutMap and RNA-seq. A Pro236Leu amino acid substitution in the highly conserved region of OsNRAMP5 is likely responsible for low $\mathrm{Cd}$ accumulation in the $\mathrm{Icd} 1$ mutant. This work provides more insight into the mechanism of $\mathrm{Cd}$ uptake and accumulation in rice, and will be helpful for developing low $\mathrm{Cd}$ accumulation rice by marker-assisted breeding.
\end{abstract}

Keywords: Rice (Oryza sativa L.), Cadmium, MutMap, RNA-seq, SNP, Transcriptome analysis

\section{Background}

Cadmium $(\mathrm{Cd})$ is a widespread toxic soil pollutant, which is easily taken up by crop plants and accumulates in the edible parts, thus posing potential health risks for humans [1]. Rice (Oryza sativa L.), as staple food for half of the world's population, is a major source of $\mathrm{Cd}$ intake for Chinese and Japanese populations, accounting

\footnotetext{
* Correspondence: happycaozhen520@163.com; cmingxue@126.com Rice Product Quality Supervision and Inspection Center, China National Rice Research Institute, Hangzhou 310006, PR, No.28 Shuidaosuo Rd., Fuyang 311400, Zhejiang, China
}

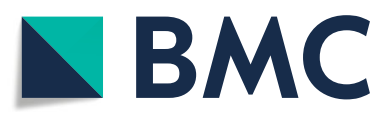

(c) The Author(s). 2019 Open Access This article is distributed under the terms of the Creative Commons Attribution 4.0 International License (http://creativecommons.org/licenses/by/4.0/), which permits unrestricted use, distribution, and reproduction in any medium, provided you give appropriate credit to the original author(s) and the source, provide a link to the Creative Commons license, and indicate if changes were made. The Creative Commons Public Domain Dedication waiver (http://creativecommons.org/publicdomain/zero/1.0/) applies to the data made available in this article, unless otherwise stated.

for $40-50 \%$ of the daily Cd intake [2-4]. Thus, it is urgent to develop strategies to reduce rice grain $\mathrm{Cd}$ accumulation and the associated health risk of $\mathrm{Cd}$ intake. Selection and breeding of low $\mathrm{Cd}$-accumulation rice varieties is one of the most economical and effective approaches to alleviating $\mathrm{Cd}$ toxicity and minimize $\mathrm{Cd}$ accumulation in rice grains grown on $\mathrm{Cd}$-contaminated soil.

There are many transport processes involved in $\mathrm{Cd}$ accumulation in rice grains, including root uptake, root-toshoot translocation by xylem, transfer from xylem to 
phloem and remobilization of $\mathrm{Cd}$ from leaves to grains [5-7]. Previous studies have identified several loci controlling these processes in rice plants by using quantitative trait locus (QTL) analyses. Three QTLs on chromosomes 3,6 , and 8 were identified as influencing $\mathrm{Cd}$ concentration in brown rice [8]. A major QTL $q l G C d 3$ for low grain $\mathrm{Cd}$ content was identified on chromosome 3 [9]. Two QTLs, $q G C d 7$ and $q C d T 7$, for grain $\mathrm{Cd}$ accumulation and $\mathrm{Cd}$ translocation, respectively, were detected on chromosome $7[10,11]$. Recently, several transporters involved in these processes have been characterized in rice plants. Natural resistance-associated macrophage protein (NRAMP) family proteins play an important role in entry of $\mathrm{Cd}$ into rice root cells $[12,13]$. OsNRAMP5 was mainly expressed in the plasma membrane of rice root and participated in manganese (Mn) and Cd uptake. Osnramp5 mutant resulted in significantly reduced $\mathrm{Mn}$ and $\mathrm{Cd}$ concentrations in rice straw and grain [14]. OsNRAMP1 showed transport activity for $\mathrm{Fe}$ and $\mathrm{Cd}$ uptake, and was more highly expressed in high $\mathrm{Cd}$-accumulating rice than low $\mathrm{Cd}$ accumulating one [15]. Zinc-regulated transporter/ironregulated transporter-like protein (ZIP) proteins and pleiotropic drug resistance (PDR)-type ATP-binding cassette $(A B C)$ transporters have been also reported to be involved in $\mathrm{Cd}$ uptake and efflux in plants. Iron (Fe) deficiency-inducible expressions of OsIRT1 and OsIRT2 enhanced $\mathrm{Cd}$ uptake and translocation in rice [16]. AtPDR8 conferred Cd tolerance in Arabidopsis by pumping $\mathrm{Cd}^{2+}$ out across the plasma membrane of root epidermal cells [17]. OsABCG36/OsPDR9 expression was significantly induced in rice roots by $\mathrm{Cd}$ exposure [18]. In addition, P-type ATPase heavy metal transporters (HMA) have been identified as the regulator for xylem $\mathrm{Cd}$ transport in rice by mediating vacuolar sequestration of $\mathrm{Cd}$ in rice roots [19]. Over-expression of OsHMA3 in rice plants enhanced $\mathrm{Cd}$ tolerance and reduced $\mathrm{Cd}$ accumulation in rice grain. These studies provide deep insight into the genetic basis of $\mathrm{Cd}$ uptake and translocation in rice. However, the comprehensive expressions of these genes in low $\mathrm{Cd}$ accumulation rice and its relationship to $\mathrm{Cd}$ accumulation have been little investigated in rice, especially for indica rice genotypes.

In past decades, microarray analysis has been a powerful tool providing important information on plants response to heavy metal stresses at the transcriptomic level. The comprehensive transcriptomic changes have been reported by various microarray analyse in rice and barley in response to $\mathrm{Cd}$, copper $(\mathrm{Cu})$ and mercury $(\mathrm{Hg})$ stress [20-22]. These microarrays analyses improved our understanding of heavy metal-responsive gene expression in plants. However, microarrays are only applicable for detecting known transcripts and always miss low abundance genes, leading to a loss of some important candidate gene information. Recently, high-throughput
RNA sequencing (RNA-seq) approach has become increasingly popular in transcriptomics studies, with increased sequencing depth and high detection sensitivity. To date, this technique has been applied in identifying the genes related to heavy metal responses in rice plants. Liu et al. [23] and $\mathrm{He}$ et al. [24] detected arseniteresponsive miRNAs and $\mathrm{Cd}$ toxicity-responsive genes in rice roots using RNAseq-based approach, and found that miRNAs and post-transcriptional alternative splicing may be involved in rice response to $\mathrm{As}$ and $\mathrm{Cd}$ exposure, respectively. Tan et al. [18] revealed universal $\mathrm{Cd}$ responsive genes in rice roots exposed to various $\mathrm{Cd}$ stresses. Differential long non-coding RNAs were detected at an early stage in the rice response to Cd stress, suggesting their role in response to Cd stress [25]. Although these studies have identified several genes and transcription factors involved in response to heavy metal stresses in rice, the molecular mechanism underlying $\mathrm{Cd}$ uptake, translocation and accumulation has not been fully understood in low $\mathrm{Cd}$ accumulation rice.

In this study, 9311 and its mutant with extremely low $\mathrm{Cd}$ content in rice grains were used to investigate the differences in $\mathrm{Cd}$ uptake and accumulation in rice seedlings exposed to $\mathrm{Cd}$ stress. The candidate gene of low $\mathrm{Cd}$ accumulation mutant was identified by MutMap method and the comprehensive transcriptional changes related to $\mathrm{Cd}$ accumulation were determined using RNA-seq. Moreover, the tissue specificity of the candidate gene and its temporal response to $\mathrm{Cd}$ exposure in $l c d 1$ and WT roots were examined by quantitative real time RT-PCR. The objective of this work is to clarify the physiological and molecular mechanism in response to $\mathrm{Cd}$ stress in low $\mathrm{Cd}$ accumulation rice, which will be helpful for developing low $\mathrm{Cd}$ accumulation rice by marker-assisted breeding.

\section{Methods \\ Plant culture and treatment}

Seeds of indica rice (cv. Yangdao 6, namely 9311), provided by the Jiangsu Lixiahe Agricultural Research Institute, were subjected to ethyl methanesulfonate (EMS) mutagenesis. Approximately $450 \mathrm{~g}$ seeds were immersed in distilled water for $12 \mathrm{~h}$, and then incubated in $1 \%$ EMS for $12 \mathrm{~h}$. After the EMS treatment, the seeds were washed in distilled water. The low $\mathrm{Cd}$ accumulation mutant (namely $l c d 1$ ) in rice grains was identified according to the grain $\mathrm{Cd}$ concentration of 35,689 M2 plants determined by inductively coupled plasma-mass spectrometry (ICP-MS; X Series 2, Thermo Fisher Corp., Waltham, MA, USA), and was further self-pollinated to obtain M5 generation of $l c d 1$. The mapping population was generated from the cross between the M5 generation of $l c d 1$ and WT and was grown in Yoshida's nutrient solution containing $0.1 \mu \mathrm{M} \mathrm{Cd}$ [26]. The F2 individuals with 
extremely high and low $\mathrm{Cd}$ accumulation in rice leaves were isolated at seedling stage and used as the mapping population for the MutMap method.

Field experiments were conducted during rice growing season from 2016 to 2017. Seeds of $l c d 1$ and WT were sterilized in $10 \% \mathrm{NaClO}$ for $20 \mathrm{~min}$ and washed with deionized water. Then seeds were germinated on moist filter paper at $37^{\circ} \mathrm{C}$ and sown in sterilized moist quartz sand. Uniform 25-day-old seedlings were subsequently respectively transplanted into the $\mathrm{Cd}$-contaminated experimental paddy field in Hangzhou (Field A, $1.5 \mathrm{mg} \mathrm{kg}^{-}$ ${ }^{1}$ of total Cd, pH 5.4), Quzhou (Field B, $2.6 \mathrm{mg} \mathrm{kg}^{-1}$ of total Cd, pH 5.8), Yiyang (Field C, $4.5 \mathrm{mg} \mathrm{kg}^{-1}$ of total $\mathrm{Cd}, \mathrm{pH} 4.8$ ) and Xiangtan (Field D, $0.35 \mathrm{mg} \mathrm{kg}^{-1}$ of total $\mathrm{Cd}, \mathrm{pH}$ 5.2). Rice plants grown in different experimental paddy fields were uniformly managed and harvested at tillering, heading, filling and maturity stages, respectively. All samples were oven dried to constant weight at $70^{\circ} \mathrm{C}$ for mineral element concentration analysis.

Hydroponics experiments were also conducted to investigate the effects of $\mathrm{Cd}$ stress on growth and $\mathrm{Cd}$ accumulation of $l c d 1$ and WT rice seedlings. Sterilized rice seeds were germinated on moist filter paper at $37^{\circ} \mathrm{C}$ and grown on a plastic mesh floating on half-strength Yoshida's nutrient solution. Uniform 15-day-old seedlings were transferred into fresh nutrient solutions for different $\mathrm{Cd}$ concentration treatments $(0$ and $5 \mu \mathrm{M})$. Each treatment was conducted in five replicated runs. After different times $(0,3,6,12 \mathrm{~h}$ and 14 days) of Cd treatment, rice plants were carefully washed with deionized water and separated into roots and shoots, immediately frozen in liquid nitrogen and then stored at $-80^{\circ} \mathrm{C}$ until use.

\section{Kinetic analyses of cd uptake in roots}

The $\mathrm{Cd}$ uptake in roots was determined according to Uraguchi et al. [27] with some modifications. Uniform 15 -day-old seedlings of $l c d 1$ and WT were transferred to the uptake solution containing $0.5 \mathrm{mM} \mathrm{CaCl} 2$ and $2 \mathrm{mM}$ MES ( $\mathrm{pH}$ 5.6) for $24 \mathrm{~h}$, and then carried out at room temperature for the uptake experiments.

For the dose-dependent $\mathrm{Cd}$ uptake experiment, rice seedlings were transferred to $1-\mathrm{L}$ plastic container with the uptake solution containing different concentrations of $\mathrm{CdCl}_{2}(0,0.1,0.25,0.5,1,5,10,15,30$ and $50 \mu \mathrm{M})$. Each treatment was replicated three times. After $1 \mathrm{~h}$ of uptake, plants were carefully washed with deionized water and separated into roots and shoots, oven dried and digested with $\mathrm{HNO}_{3}$ for $\mathrm{Cd}$ concentration analysis. Values of $K m$ and Vmax for each genotype were calculated using software (GraphPadPRISM4; GraphPad Software Inc., CA, USA).

For the time-course $\mathrm{Cd}$ uptake experiment, rice seedlings were transferred to $1-\mathrm{L}$ plastic container with the uptake solution containing $5 \mu \mathrm{M} \mathrm{CdCl} 2$ for different time treatments $(0,5,10,30,60,90,120$ and $180 \mathrm{~min})$. Each treatment was replicated three times. The concentration of $\mathrm{Cd}$ in roots was determined as described below.

\section{Determination of metal elements concentrations}

The metal elements $(\mathrm{Cd}, \mathrm{Fe}, \mathrm{Mn}, \mathrm{Zn}$ and $\mathrm{Cu}$ ) concentrations were determined by ICP-MS according to Cao et al. [28]. Briefly, dried rice root, shoot and grain samples $(0.25 \mathrm{~g})$ were digested in concentrated $\mathrm{HNO}_{3}$, and diluted to $50 \mathrm{~mL}$ by deionized water for metal elements determination.

\section{MutMap analysis}

DNAs for MutMap analysis were extracted from rice leaves with DNeasy Plant Mini Kit (Qiagen, Hilden, Germany). Two parents and two bulked DNA pools were used for MutMap analysis. The bulked DNA were prepared by mixing DNA equally from $31 \mathrm{~F} 2$ individuals with extremely high and low $\mathrm{Cd}$ accumulation in rice leaves respectively. DNA quality and concentration were checked using the NanoPhotometer ${ }^{\circ}$ spectrophotometer (IMPLEN, CA, USA) and Qubit DNA Assay Kit in Qubit $^{\circledR}$ 2.0 Flurometer (Life Technologies, CA, USA). Sequencing libraries were generated using Truseq Nano DNA HT Sample preparation Kit (Illumina, USA) and were sequenced by Illumina HiSeq4000 platform (Illumina, CA, USA).

The raw data (WT parent: SRR8695240, lcd1 parent: SRR8695241, extremely high Cd accumulation pool: SRR8695238, extremely low Cd accumulation pool: SRR8695239) were filtered by phred quality score to remove adapter sequences and low-quality bases. The clean reads were aligned to the 9311 reference genome (ftp://ftp.ensemblgenomes.org/pub/ plants/release-36/fasta/oryza_indica/dna/) using BWA software. Alignment files were converted to BAM files through SAMtools software and applied to GATK to identify reliable SNPs. The SNP-index of two pools were calculated using sliding window methods and the difference between the SNP-index of two pools was calculated as $\Delta \mathrm{SNP}$-index.

\section{RNA-seq analysis}

Total RNAs for RNA-Seq analysis were extracted from rice roots of $l c d 1$ and WT under $\mathrm{Cd}$ exposure with RNeasy Plant kit (Qiagen, Hilden, Germany). RNA quality and concentration were determined by NanoPhotometer $^{\bullet}$ spectrophotometer (IMPLEN, CA, USA) and Qubit $^{\circ}$ RNA Assay Kit in Qubit $^{\circ}$ 2.0 Flurometer (Life Technologies, CA, USA). Sequencing libraries were generated using NEBNext ${ }^{\circ}$ Ultra $^{\text {at }}$ RNA Library Prep Kit for 
Illumina ${ }^{\circ}$ (NEB, USA) and were sequenced on an Illumina Hiseq platform (Illumina, CA, USA).

The raw sequences for WT (SRR8718745, SRR8718748 and SRR8718749, three biological replicates) and $l c d 1$ (SRR8718744, SRR8718746 and SRR8718747, three biological replicates) libraries were filtered using phred quality score to remove adapter sequences and low-quality bases. In high-quality reads, the sequences were trimmed and mapped to the 9311 reference genome using Hisat2. The best match was used to annotate genes and assign gene ontology information. FPKM values (fragments per kilobase of exon model per million mapped reads) were calculated to estimate gene expression levels. False positive and false negative errors were corrected by calculating the FDR (false discovery rate) adjusted q-values. The DEGs (differentially expressed genes) between $l c d 1$ and WT under Cd exposure were selected based on normalized read count, and fold change $(l c d 1 / \mathrm{WT}) \geq 1.5$ and q-value $<0.05$ were used as threshold values by using the DESeq $R$ package (1.18.0). Gene ontology (GO) enrichment analysis of DEGs between $l c d 1$ and WT under Cd exposure was performed using the GOseq R-package with q-value $<0.05$.

\section{Quantitative real-time RT-PCR}

The tissue specificity of the candidate gene and its temporal expression under $\mathrm{Cd}$ exposure were examined by quantitative real time RT-PCR (qPCR). The mixture of first-strand cDNA from $1 \mu \mathrm{g}$ of total RNA served as the templates for qPCR analysis using ReverTra Ace ${ }^{\circ}$ qPCR RT Master Mix (Toyobo, Japan). The primers used for qPCR were designed by Primer Premier 5.0 (Premier, Palo Alto, California, USA) as listed in Additional file 1: Table S1. The qPCR reactions were run on a QuantStudio 3 (Applied Biosystems, Thermo Fisher Scientific, Waltham, MA, USA), with a total reaction volume of $25 \mu \mathrm{L}$ containing $2 \mu \mathrm{L}$ of diluted cDNA template, $12.5 \mu \mathrm{L}$ of SYBR Green Realtime PCR Master Mix, $1 \mu \mathrm{L}$ of $10 \mu \mathrm{M}$ forward and reverse primer, and $8.5 \mu \mathrm{L}$ of nuclease-free water. The following reaction conditions were applied: incubation at $95^{\circ} \mathrm{C}$ for $60 \mathrm{~s}, 40$ cycles of denaturation at $95^{\circ} \mathrm{C}$ for $15 \mathrm{~s}$, annealing at $55^{\circ} \mathrm{C}$ for $15 \mathrm{~s}$ and extension at $72{ }^{\circ} \mathrm{C}$ for $45 \mathrm{~s}$, followed by the dissociation stage for melt curve analysis (from 60 to $94{ }^{\circ} \mathrm{C}$ ). All of the samples were run with three replicates, and three no-template controls (NTC) were included in every run to monitor possible DNA contamination. ACTIN-1 was used as a control to calculate the relative gene expression levels.

To optimize qPCR conditions for each primer pair, PCR amplification specificity and efficiency were examined according to the MIQE guidelines [29]. The specificity of the PCR amplification was checked with a melt curve analysis. The result showed that the amplified product yielded a single peak at the melting temperature (Tm) for each gene, indicating that primer pairs for qPCR are highly specific. The PCR amplification efficiency was assessed using 5-fold serial dilution calibration-curve. The slopes of calibration curves range from -3.53 to -3.48 , with corresponding $R^{2}$ and efficiencies of $0.988-0.997$ and $92.1-93.9 \%$, respectively (Additional file 2: Table S2). conforming that the PCR amplification efficiency for each primer pair meets the MIQE recommended range (90.0-105.0\%). The samples were normalized using ACTIN-1 expression and the relative gene expression levels were analyzed using the $2^{(-\Delta \Delta C T)}$ method due to that the amplification efficiencies of the target and reference were similar (Additional file 2: Table S2).

\section{Statistics}

Data were expressed as mean \pm standard error of at least three biological replicates for each sample. Statistical analyses were performed using the statistical software graphpad prism (Graphpad Software, San Diego, CA, USA). Statistical significance was assessed using Duncan's multiple comparison at $P<0.05$ level.

\section{Results}

\section{Isolation and characterization of the Icd 1 mutant}

We isolated a mutant $(l c d 1)$ displaying extremely low $\mathrm{Cd}$ content in rice grain from an EMS-mutagenized indica rice 9311. The $l c d 1$ mutant was identified in screening for grains Cd concentration from among 35,689 M2 plants grown on $\mathrm{Cd}$-contaminated paddy field and was further self-pollinated to obtain $\mathrm{M}_{5}$ generation of $l c d 1$. At maturity, there were no obvious differences in plant height, tiller number and panicle morphology between $l c d 1$ and WT grown in different paddy fields (Fig. 1a, b, Additional file 3: Table S3). However, the concentrations of $\mathrm{Cd}$ in $l c d 1$ grains from all paddy fields were extremely low, ranging from 0.02 to $0.13 \mathrm{mg} \cdot \mathrm{kg}^{-1}$, which was much lower than the maximum limit of $0.2 \mathrm{mg} \cdot \mathrm{kg}^{-1}$ for $\mathrm{Cd}$ in rice; whereas the corresponding $\mathrm{Cd}$ concentrations in WT grains were $1.02-4.44 \mathrm{mg} \cdot \mathrm{kg}^{-1}$ (Fig. 1c). The grain $\mathrm{Cd}$ concentrations in $l c d 1$ decreased by $96.2-98.0 \%$ compared with those in WT. Similar results were observed for root and shoot $\mathrm{Cd}$ concentrations of $l c d 1$ at tillering, heading and filling stages (Fig. 1d, e). The other metal concentrations, such as $\mathrm{Zn}, \mathrm{Cu}$ and $\mathrm{Fe}$ in grains were not significantly different between $l c d 1$ and WT grown in most paddy fields. However, (Mn concentrations in $l c d 1$ grains from all paddy fields were significantly lower than those in WT (Additional file 4: Figure S1).

Rice seedlings of $l c d 1$ and WT were exposed to $5 \mu \mathrm{M}$ $\mathrm{Cd}$ in hydroponics. Under control condition, there were no visible differences in plant height, root length, root and shoot weights between $l c d 1$ and WT. When grown 


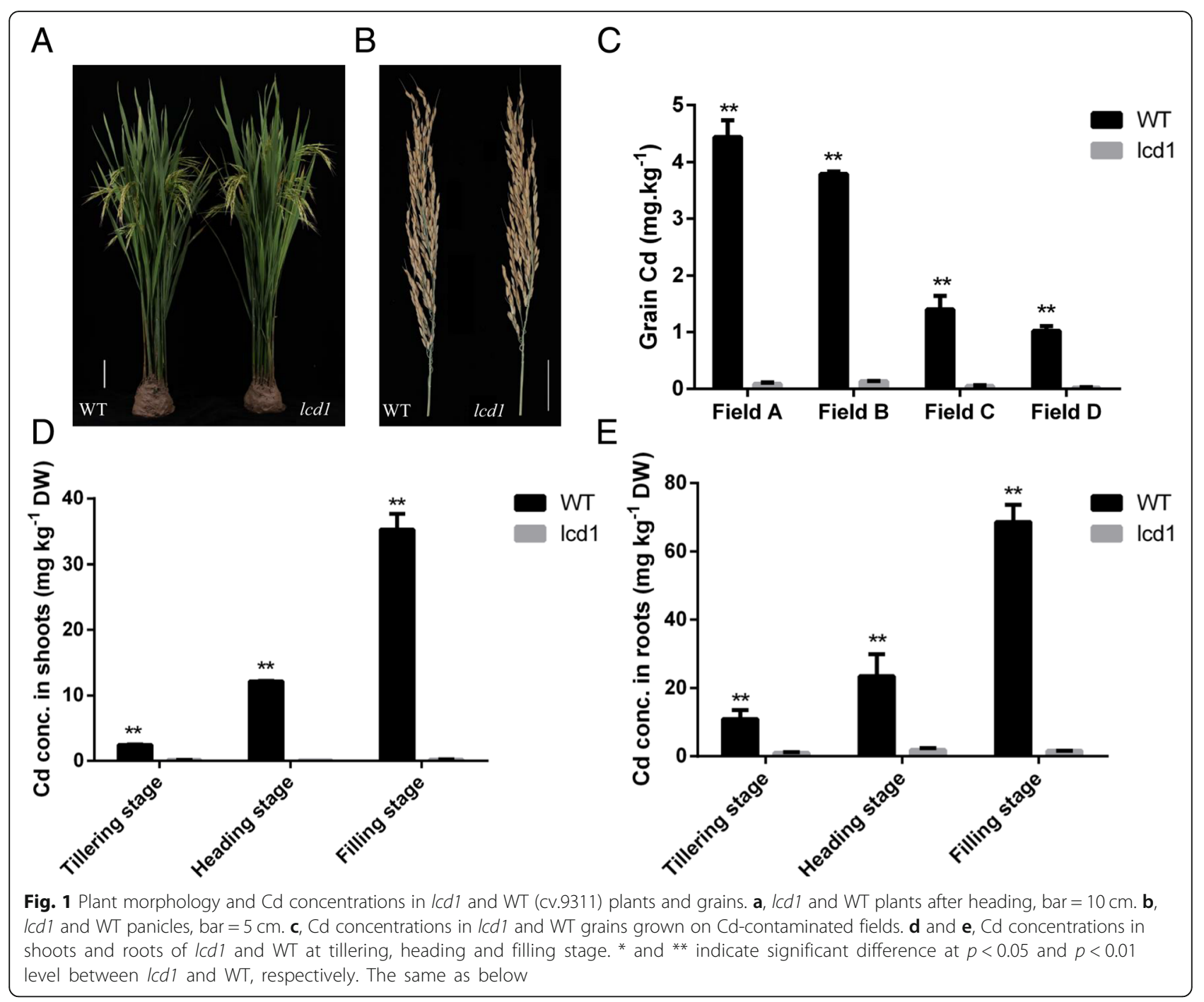

in the presence of $5 \mu \mathrm{M} \mathrm{Cd}$, both $l c d 1$ and WT showed decreases in plant height and shoot weight compared with control, however, $l c d 1$ shoots were much longer than WT in the presence of $5 \mu \mathrm{M} \mathrm{Cd}$ (Fig. 2a-d). Moreover, $l c d 1$ accumulated less $\mathrm{Cd}$ in both shoots and roots compared with WT, irrespective of $\mathrm{Cd}$ treatment (Fig. $2 \mathrm{e}, \mathrm{f})$. The concentrations of $\mathrm{Cu}$ and $\mathrm{Zn}$ in both shoots and roots did not differ significantly between $l c d 1$ and WT, however, the concentrations of $\mathrm{Mn}$ in both shoots and roots were significantly lower in $l c d 1$ than in WT, while the shoot Fe concentration was relatively lower in $l c d 1$ than in WT (Additional file 5: Figure S2).

The Cd uptake abilities of $l c d 1$ and WT were further determined by a dose- and time-dependent $\mathrm{Cd}$ uptake in roots. The Cd uptake by roots was lower in $l c d 1$ than in WT under all $\mathrm{Cd}$ treatment concentrations (Fig. 3a). The $V_{\text {max }}$ of $l c d 1\left(162.00 \pm 9.11 \mathrm{nmol} \mathrm{g}^{-1} \mathrm{DW} \mathrm{h}^{-1}\right)$ was lower than that of WT $\left(523.70 \pm 33.27 \mathrm{nmol} \mathrm{g}^{-1} \mathrm{DW} \mathrm{h}{ }^{-}\right.$ $\left.{ }^{1}\right)$, and the value of $K m$ was greater in $l c d 1(23.20 \pm$
$2.83 \mu \mathrm{M})$ than in WT $(9.26 \pm 1.67 \mu \mathrm{M})$ (Table 1). The time-course of $\mathrm{Cd}$ uptake was 1.7-2.4 times higher in WT than in $l c d 1$ through $180 \mathrm{~min}$ of $\mathrm{Cd}$ exposure (Fig. $3 \mathrm{~b})$. These results show that the $\mathrm{Cd}$ uptake ability of lcd1 is much lower than that of WT.

\section{Genetic analysis and identification of the candidate region of the Icd 1 mutant by MutMap analysis}

For rapid identification of the gene controlling the low $\mathrm{Cd}$ accumulation phenotype of the $l c d 1$ mutant, we crossed the $l c d 1$ mutant to WT 9311 in 2016 to obtain F1 progeny. F1 plants were self-pollinated to generate F2 progeny in 2017. 439 F2 individuals were grown in Yoshida's nutrient solution containing $0.1 \mu \mathrm{M} \mathrm{Cd}$. The progeny segregated in a 3:1 ratio $(327: 112)$ for WT phenotype and low $\mathrm{Cd}$ accumulation phenotype, respectively, indicating that the low $\mathrm{Cd}$ accumulation phenotype of the $l c d 1$ mutant is caused by a single recessive mutation. We combined DNA form 31 F2 progeny that 

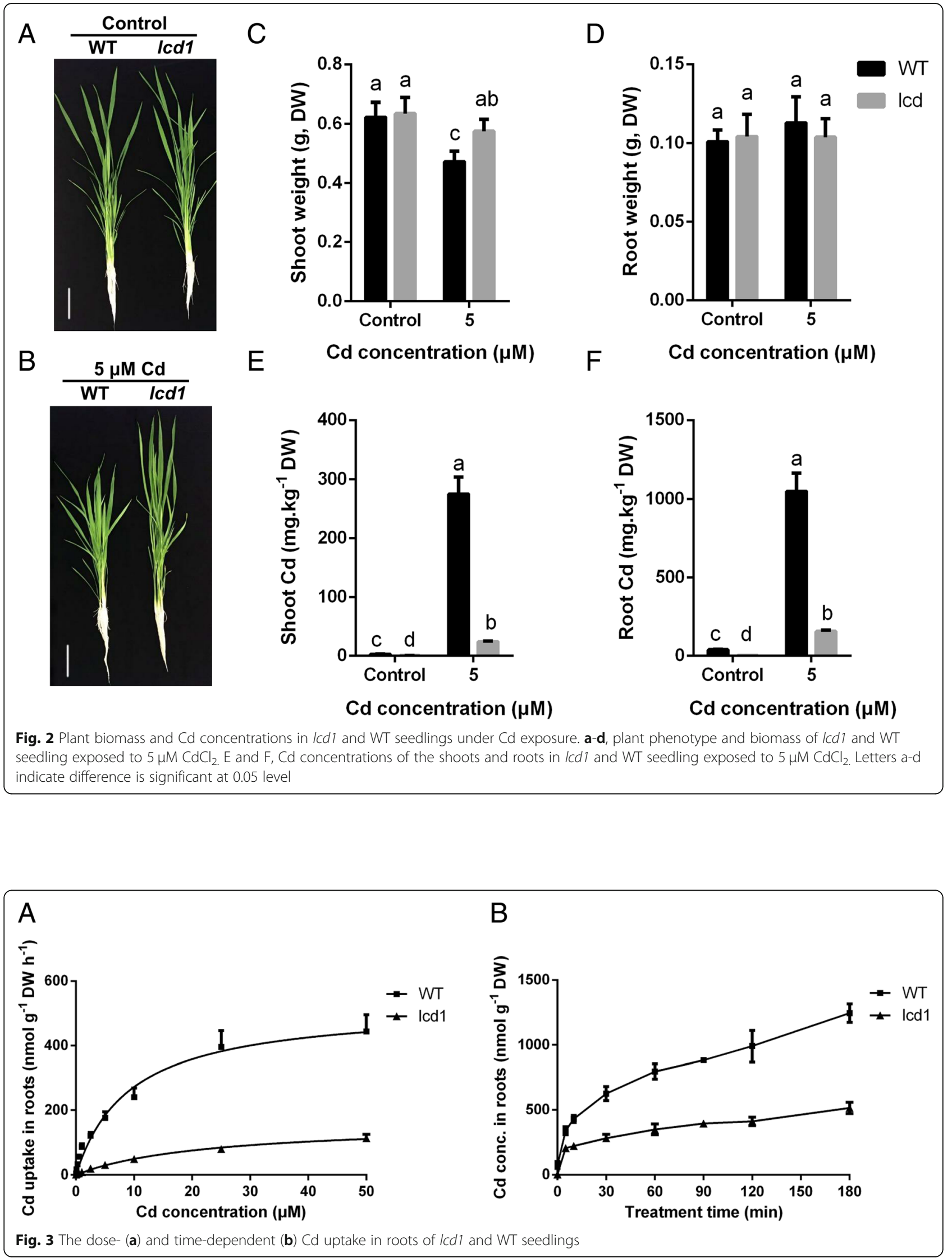
Table 1 The Michaelis-Menten equation parameters of root $\mathrm{Cd}$ uptake in $\mid c d 1$ and WT under different $\mathrm{Cd}$ exposure. Data are presented as means \pm SE $(n=3)$

\begin{tabular}{|c|c|c|c|}
\hline Rice genotypes & $V_{\max }\left(\mathrm{nmol} \mathrm{g}^{-1} \mathrm{DW} \mathrm{h}^{-1}\right)$ & $\mathrm{Km}(\mu \mathrm{M})$ & $r^{2}$ \\
\hline$\overline{W T}$ & $523.70 \pm 33.27$ & $9.26 \pm 1.67$ & 0.9823 \\
\hline Icd & $162.00 \pm 9.11$ & $23.20 \pm 2.83$ & 0.9950 \\
\hline
\end{tabular}

displayed extremely high (namely $\mathrm{H} 2 \_\mathrm{H} 31$ pool) and low $\mathrm{Cd}$ accumulation phenotype (namely H2_L31 pool) and subjected them to whole-genome sequencing using Illumina HiSeq4000 platform. We obtained 22,199,781, 900 and 20,232,345,600 cleaned bases for Pool H2_H31 and H2_L31, respectively. These reads were aligned to the 9311 reference genome using the BWA software resulting in the identification of 1055 SNP positions.

For each SNP position, the value of SNP-index was obtained and a graph relating SNP positions and $\triangle \mathrm{SNP}-$ index (the difference of the SNP-index of two pools) were generated for all 12 chromosomes of rice. As we expected, $\triangle \mathrm{SNP}$-index was distributed randomly around 0 for most parts of the genome (Additional file 6: Figure S3). Finally, we obtained the candidate region containing a cluster of SNPs with $\triangle \mathrm{SNP}$-index values ranging from 0.6 to 1 on chromosome 7 (Fig. 4a).

\section{Identification of the causal SNPs of the Icd 1 mutant}

There were nine SNPs with $\triangle$ SNP-index ranging from 0.6 to 1 identified in the candidate region, of which most SNPs located in non-coding region or had no gene annotation information (Table 2). A SNP at nucleotide position $8,887,787$ corresponded to the seventh exon of the gene OsNRAMP5 (BGIOSGA024510, Os07g0257200), previously identified as an important transporter responsible for Mn and Cd uptake. This SNP led to a $\mathrm{C}$ to $\mathrm{T}$ transition at codon 236, resulting in replacement of a Pro (CCC) residue by Leu (CTC) in OsNRAMP5 (Fig. 4b). Sequence analysis confirmed the mutation site in the $l c d 1$ mutant and multiple protein sequence comparison indicated that the residue affected was highly conserved in different crop plants (Fig. 4c, d), suggesting that the Pro236Leu substitution is likely responsible for the low $\mathrm{Cd}$ accumulation phenotype of the $l c d 1$ mutant.

The tissue specificity and temporal expression level of OsNRAMP5 were further detected in $l c d 1$ and WT under $\mathrm{Cd}$ exposure. OsNRAMP5 was expressed exclusively in WT root and little of its mRNA was detected in WT shoot (Fig. 5a). Moreover, OsNRAMP5 expression markedly increased with enhancing $\mathrm{Cd}$ treatment time in both WT and $l c d 1$ roots compared with the control. However, $l c d 1$ root showed a higher OsNRAMP5 expression at 3 and $6 \mathrm{~h}$ after $\mathrm{Cd}$ treatment, but significant lower expression at $12 \mathrm{~h}$ after Cd treatment than WT root (Fig. 5b), indicating a difference in Cd response pattern between $l c d 1$ and WT root.

\section{Transcriptome analysis of the Icd1 mutant under cd exposure by RNA-seq}

To clarify how the mutation in OsNRAMP5 affects transcript levels of other genes involved in $\mathrm{Cd}$ accumulation in rice roots. Transcriptome of $l c d 1$ and WT roots under $\mathrm{Cd}$ exposure were investigated by RNA-seq analysis. 15day-old rice seedlings of $l c d 1$ and WT were exposed to $5 \mu \mathrm{M} \mathrm{Cd}$ for $6 \mathrm{~h}$, and root samples were used for sequencing on an Illumina platform. An average of $\sim 51.5$ million clean reads per sample was attained from $l c d 1$ and WT root cDNA libraries, among which more than $85 \%$ was uniquely mapped to the 9311 reference Genome (ftp://ftp.ensemblgenomes.org/pub/plants/release36/fasta/oryza_indica/dna/). 25,090 expressed genes were detected in Cd-exposed WT root and 24,808 expressed genes in $\mathrm{Cd}$-exposed $l c d 1$ root, among which 24,102 genes were common ones, indicating similar genetic background between the two genotypes (Fig. 6a). The list of detected genes from RNA-Seq for $l c d 1$ and WT under Cd exposure were provided in supplementary material (Additional file 7). A total of 1208 genes were differentially expressed between $l c d 1$ and WT roots using threshold values of fold change $(l c d 1 / \mathrm{WT}) \geq 1.5$ and q-value $<0.05$, including 577 up-regulated and 631 down-regulated ones (Fig. 6b). GO classification of biological process, cellular component and molecular function of the DEGs were all significantly enriched in transmembrane transport (Fig. 6c), indicating that transmembrane transport process plays an important role in differential $\mathrm{Cd}$ accumulation between $l c d 1$ and WT roots.

The changes in transcriptional levels of NRAMP, ZIP, HMA and $A B C$ family genes, previously identified as important genes involved in $\mathrm{Cd}$ transmembrane transport, were further analyzed between $l c d 1$ and WT (Table 3). In general, $l c d 1$ root showed relatively lower expressions in NRAMP and $A B C$ family genes, and higher expressions in ZIP and HMA family genes than WT root under $\mathrm{Cd}$ exposure. Among them, four genes (OsNRAMP1, OsABCG36/OsPDR9, OsZIP9 and OsHMA3) displayed larger relative changes in their expression levels between $l c d 1$ and WT roots under Cd exposure compared with the other genes, indicating that they are involved in differential $\mathrm{Cd}$ accumulation between $l c d 1$ and WT roots.

\section{Discussion}

Rice is a major dietary intake source of $\mathrm{Cd}$ for Asian populations, therefore, reducing rice grain $\mathrm{Cd}$ accumulation is very important for human health $[2,4]$. Selection and breeding of low $\mathrm{Cd}$-accumulation rice is recognized 
A

Chromosome 7

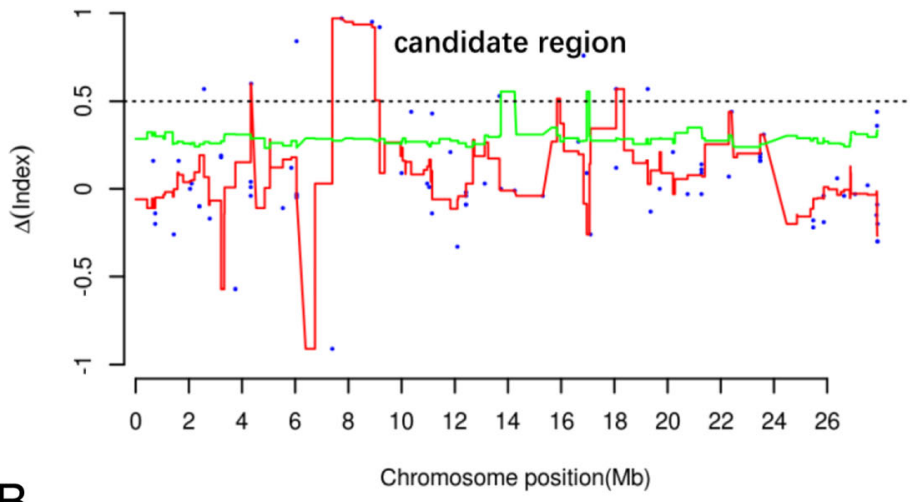

B

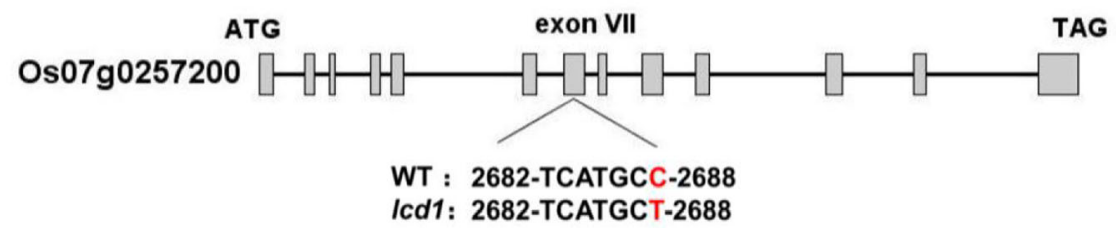

C
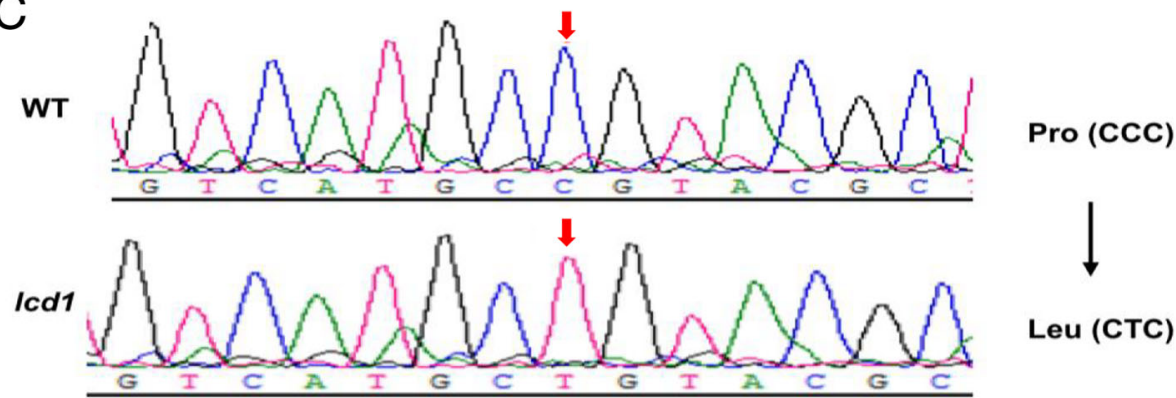

Leu (CTC)

D

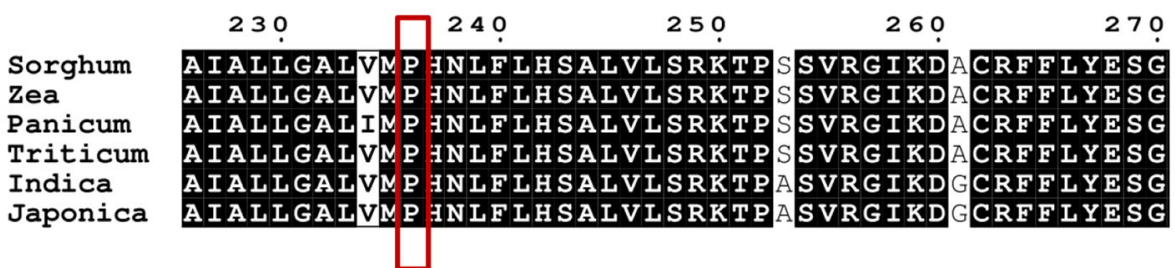

Fig. 4 Identification of the I $c d 1$ mutant by MutMap. a, $\Delta$ SNP-index plots of two pools on chromosome 7 generated by MutMap analysis. $\mathbf{b}$. Structure of the OsNRAMP5 gene in Icd1 and WT. Gray boxes and black lines represent exons and introns in the OsNRAMP5 gene, respectively. SNP location is indicated below the gene structure with red font. c, Confirmation of SNP in the Icd1 mutant by Sanger sequencing. The SNP is indicated with red arrow. d, Homology comparison of the OsNRAMP5 protein in different crop plants. * indicates the identical amino acids, red box indicates the amino acid mutation location

as the most economical and effective approach to reduce rice grain $\mathrm{Cd}$ concentration and associated $\mathrm{Cd}$ intake risk for humans [30]. In this study, we succeeded to obtain a non-transgenic low $\mathrm{Cd}$ accumulating rice mutant, lcd1, by EMS mutagenesis from 9311, a well-known commercial indica rice cultivar with its full genome sequence available. The $l c d 1$ mutant had the similar agronomic traits to WT 9311 when grown on moderately or severely $\mathrm{Cd}$-contaminated fields, but accumulated extremely low $\mathrm{Cd}$ in grains and plants (Additional file 3: Table S3, Fig. 1). Physiological studies in hydroponic culture further showed that $l c d 1$ shoots were much longer than those of WT in the presence of $5 \mu \mathrm{M}$ $\mathrm{Cd}$, and had less $\mathrm{Cd}$ accumulation in shoots and roots 
Table 2 Summary of SNPS showing $\triangle$ SNP-index from 0.6 to 1 within the candidate region

\begin{tabular}{lllllll}
\hline$\Delta$ SNP-index & Position & Ref & Alt & Mutated gene & Mutation Type & Gene Annotation \\
\hline 0.95 & $8,887,787$ & C & T & BGIOSGA024510 & Missense (P to L) & metal transporter Nramp5 \\
0.92 & $9,174,237$ & C & T & BGIOSGA024502 & Intron mutation & GHD7 protein \\
0.57 & $2,570,339$ & G & A & BGIOSGA024818 & 5'-UTR mutation & Hypothetical protein \\
0.57 & $18,066,507$ & C & A & BGIOSGA025813 & 3'-UTR mutation & Hypothetical protein \\
0.57 & $19,252,302$ & T & A & BGIOSGA025883 & Missense (R to W) & Hypothetical protein \\
0.97 & $7,743,062$ & G & A & None & $/$ & $/$ \\
0.84 & $6,051,970$ & T & A & None & $/$ & $/$ \\
0.76 & $16,841,982$ & G & T & None & $/$ & $/$ \\
0.6 & $4,343,274$ & G & A & None & $/$ & / \\
\hline
\end{tabular}

identified by MutMap analysis

Ref: reference base in WT, Alt: altered base in the $I c d 1$ mutant

compared with WT (Fig. 2). Moreover, root Cd uptake ability of $l c d 1$ was much lower than that of WT (Fig. 3, Table 1). These results indicate that the $l c d 1$ mutant has lower Cd-accumulating ability and higher tolerance to $\mathrm{Cd}$ stress than WT. It is noteworthy that the $l c d 1 \mathrm{mu}-$ tant do not show any inhibition in rice growth compared with WT, although the concentrations of Mn were significantly lower in $l c d 1$ rice seedling and grain than those in WT (Additional file 4: Figure S1, Additional file 5: Figure S2), suggesting the potential use of the $l c d 1$ mutant in reducing intake risk of $\mathrm{Cd}$ from rice consumption without yield penalty.

For rapid identification of the gene controlling the low $\mathrm{Cd}$ accumulation phenotype of the $l c d 1$ mutant, MutMap, a method based on whole-genome sequencing of bulked DNA of F2 segregating population was used in the present study. Compared with conventional mapbased cloning, MutMap method can rapidly identify mutant genes and QTLs by using F2 progeny derived from the cross of the mutant and its wild type [31, 32]. Previous studies have identified some genes using MutMap method in rice. OsRR22, responsible for the salinitytolerance phenotype for the hst1 mutant, has been identified by a MutMap method [31]. WB1, a regulator of endosperm development in rice, has been identified by a modified MutMap method [33]. In the present study, MutMap analysis, sequencing verification and homologous comparison results showed that a Pro236Leu amino acid substitution in a highly conserved region of OsNRAMP5 is likely responsible for the low Cd uptake and accumulation phenotype of the $l c d 1$ mutant (Fig. 4). In line with our study, Ishikawa et al. [13] isolated three low $\mathrm{Cd}$ accumulation mutants from ion-beam irradiated seeds of japonica rice cultivar Koshihikari, namely $l c d$ $k m t 1, l c d-k m t 2$ and $l c d-k m t 3$. Gene identification results showed that low $\mathrm{Cd}$ accumulation phenotype of three mutants were caused by 1-bp deletion, 433-bp insertion and $\sim 277 \mathrm{~kb}$ deletion in OsNRAMP5 respectively. In the present study, we isolated the indica rice $l c d 1$ mutant with the nonsynonymous mutation at codon 236 $(\mathrm{CCC} \rightarrow \mathrm{CTC})$ in OsNRAMP5. The lcd1 mutant had similar extremely low $\mathrm{Cd}$ accumulation phenotype to the
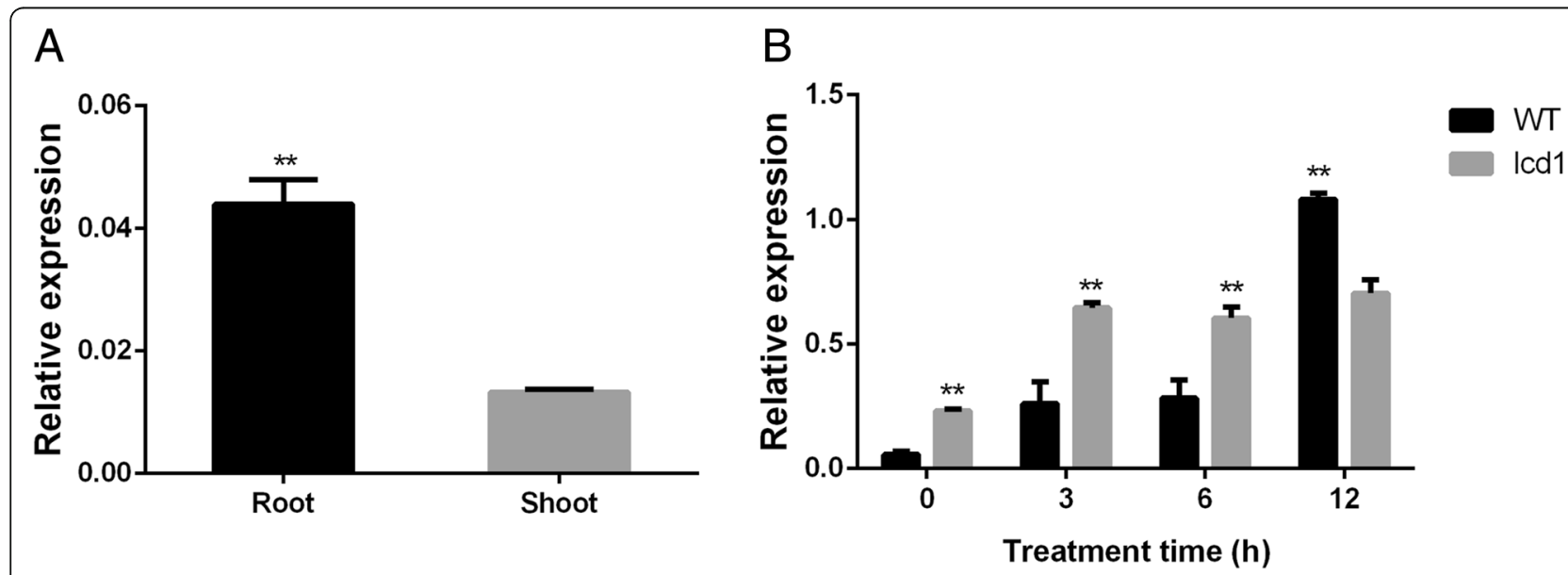

Fig. 5 The tissue specificity of the OSNRAMP5 gene and its temporal response to Cd exposure in Icd1 and WT roots. a, Relative expression of OSNRAMP5 in WT root and shoot. b. Temporal responses of OsNRAMP5 in Icdl and WT roots to Cd exposure 


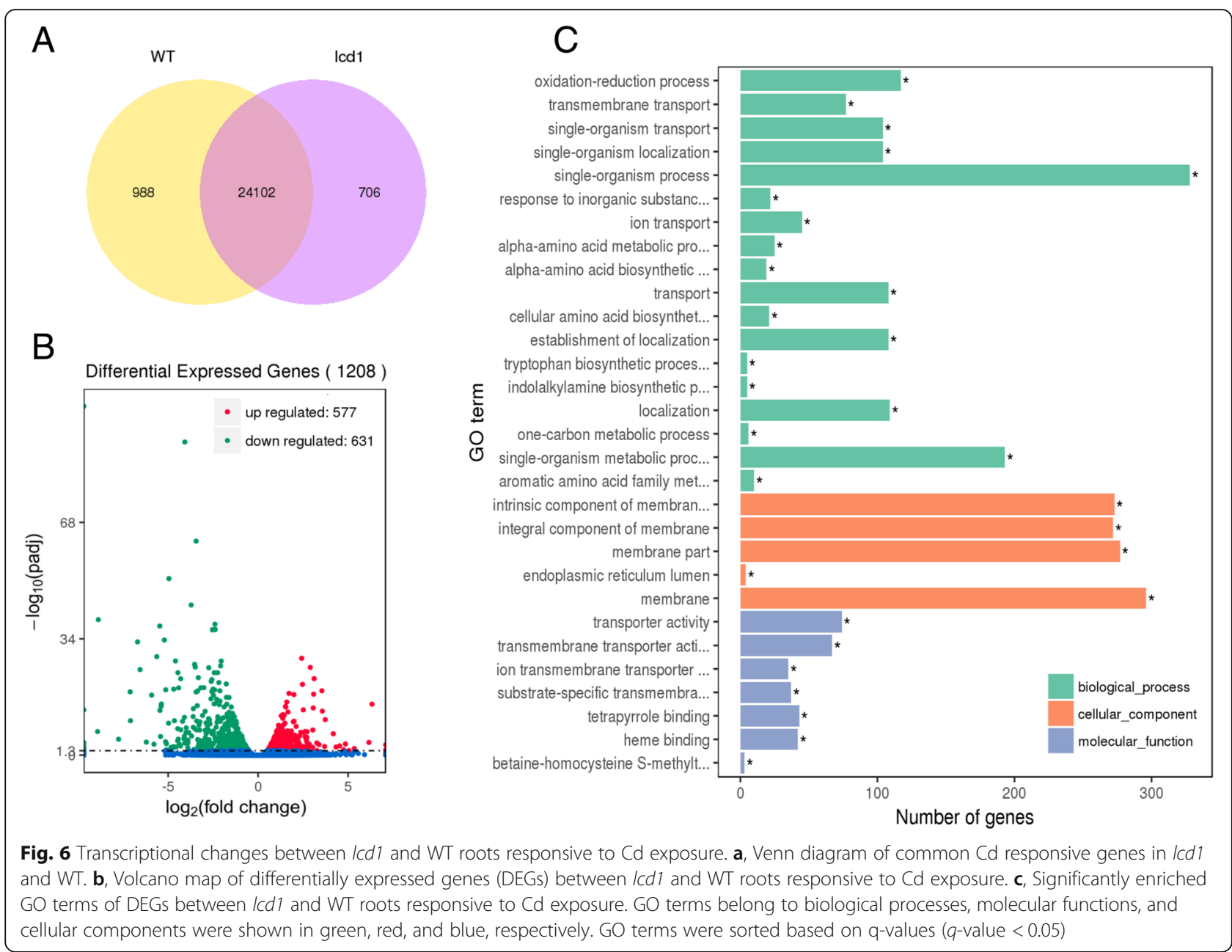

reported OsNRAMP5 mutants [13], but differed in the mutation site of the OsNRAMP5 gene, indicating that it may be a new OsNRAMP5 allelic mutant in rice. Furthermore, Tang et al. [34] and Sasaki et al. [14] reported that knockout of OsNRAMP5 using the CRISPR/Cas9 system and T-DNA insertion produced low Cdaccumulating indica rice (cv Huazhan) and japonica rice (cv Zhonghua11), respectively, indicating that OsNRAMP5 is a major transporter responsible for Cd uptake in rice. In the present study, a Pro236Leu amino acid substitution likely results in a defective OsNRAMP5 in the $l c d 1$ mutant. Our results supported previous findings that OsNRAMP5 is a major transporter responsible for $\mathrm{Cd}$ uptake in rice. However, in the present study, the $O s N$ RAMP5 expressions in $l c d 1$ root were increased at 3 and $6 \mathrm{~h}$ after Cd treatment, but decreased at $12 \mathrm{~h}$ after $\mathrm{Cd}$ treatment than those in WT root (Fig. 5b). This might be due to the fact that low $\mathrm{Cd}$ concentration in the $l c d 1 \mathrm{mu}-$ tant promotes $\mathrm{Cd}$ absorption by inducing OsNRAMP5 expression during the early stage of $\mathrm{Cd}$ exposure.

To clarify the molecular mechanism underlying $\mathrm{Cd}$ uptake, translocation and accumulation in the $l c d 1$ mutant, transcriptome changes between $l c d 1$ and WT under $\mathrm{Cd}$ exposure were investigated by RNA-seq analysis. RNA-seq provides an effective approach to identify the whole transcriptome changes in rice responsive to heavy metal stresses. Previous studies have demonstrated the transcriptional changes in rice plants responsive to Cd using high-throughput RNA sequencing [18, 24, 25]. Similar transcriptome investigations were performed in maize [35], barley [36] and bean (Phaseolus vulgaris L.) [37] under $\mathrm{Cd}, \mathrm{Zn}$ and $\mathrm{Cu}$ stress. In this study, a total of 1208 DEGs were identified between $l c d 1$ and WT roots under $\mathrm{Cd}$ exposure, and most were significantly enriched in transmembrane transport (Fig. 6), indicating that the transmembrane transport process contributes to differential $\mathrm{Cd}$ response and accumulation between $l c d 1$ and WT roots. Hence, the changes in transcriptional levels of NRAMP, ZIP, HMA and ABC family genes, previously identified as important genes involved in Cd transmembrane transport, were further examined between $l c d 1$ and WT (Table 3). Four genes, OsNRAMP1, OsABCG36/ OsPDR9, OsZIP9 and OsHMA3 displayed larger relative changes in their expression levels between $l c d 1$ and WT 
Table 3 Comparison of gene expressions related to $\mathrm{Cd}$ transmembrane transport between Icd 1 and WT roots under $\mathrm{Cd}$ exposure using RNA-seq analysis

\begin{tabular}{|c|c|c|c|c|c|}
\hline Gene ID & Gene locus & Gene names & Icd1 FPKM & WT FPKM & Fold change (Icdi/NT) \\
\hline \multicolumn{6}{|l|}{ OsNRAMP family } \\
\hline BGIOSGA025476 & Os07g0258400 & OSNRAMP1 & 6.20 & 19.44 & 0.33 \\
\hline BGIOSGA011239 & Os03g0208500 & OsNRAMP2 & 19.56 & 24.24 & 0.83 \\
\hline BGIOSGA020686 & Os06g0676000 & OsNRAMP3 & 40.09 & 62.85 & 0.66 \\
\hline BGIOSGA007187 & Os02g0131800 & OsNRAMP4 & 217.56 & 147.96 & 1.51 \\
\hline BGIOSGA024510 & Os07g0257200 & OsNRAMP5 & 47.21 & 43.86 & 1.11 \\
\hline BGIOSGA001567 & Os01g0503400 & OsNRAMP6 & 12.06 & 14.16 & 0.88 \\
\hline BGIOSGA035937 & Os12g0581600 & OSNRAMP7 & 9.67 & 12.98 & 0.77 \\
\hline \multicolumn{6}{|l|}{ OsZIP family } \\
\hline BGIOSGA010092 & Os03g0667500 & OSIRT1 & 1.99 & 2.49 & 0.80 \\
\hline BGIOSGA010094 & Os03g0667300 & OsIRT2 & 0.02 & 0.02 & 1.06 \\
\hline BGIOSGA000021 & Os01g0972200 & OsZIP1 & 0.26 & 0.23 & 1.10 \\
\hline BGIOSGA010542 & Os03g0411800 & OsZIP2 & 70.14 & 93.40 & 0.75 \\
\hline BGIOSGA014364 & Os04g0613000 & OsZIP3 & 0.91 & 1.12 & 0.82 \\
\hline BGIOSGA028188 & Os08g0207401 & OsZIP4 & 44.19 & 27.47 & 1.61 \\
\hline BGIOSGA020032 & Os05g0472700 & OsZIP5 & 72.79 & 46.94 & 1.55 \\
\hline BGIOSGA018749 & Os05g0164800 & OsZIP6 & 58.52 & 60.36 & 0.97 \\
\hline BGIOSGA019328 & Os05g0198400 & OsZIP7 & 91.10 & 72.76 & 1.25 \\
\hline BGIOSGA025423 & Os07g0232800 & OsZIP8 & 18.26 & 12.97 & 1.41 \\
\hline BGIOSGA020030 & Os05g0472400 & OsZIP9 & 41.71 & 14.70 & 2.84 \\
\hline BGIOSGA023103 & Os06g0566201 & OsZIP10 & 22.26 & 9.91 & 2.25 \\
\hline BGIOSGA018313 & Os05g0316100 & OsZIP11 & 39.91 & 34.43 & 1.16 \\
\hline \multicolumn{6}{|l|}{ OsHMA family } \\
\hline BGIOSGA020639 & Os06g0690700 & OsHMA1 & 12.91 & 11.42 & 1.13 \\
\hline BGIOSGA020589 & Os06g0700700 & OsHMA2 & 101.99 & 95.74 & 1.07 \\
\hline BGIOSGA024568 & Os07g0232900 & OsHMA3 & 12.45 & 9.80 & 1.27 \\
\hline BGIOSGA007732 & Os02g0196600 & OsHMA4 & 105.93 & 82.41 & 1.29 \\
\hline BGIOSGA016903 & Os04g0556000 & OSHMAS & 42.69 & 37.76 & 1.13 \\
\hline BGIOSGA007052 & Os02g0172600 & OsHMAG & 19.51 & 21.01 & 0.93 \\
\hline BGIOSGA028879 & Os08g0486100 & OsHMAT & 20.66 & 17.04 & 1.21 \\
\hline BGIOSGA011343 & Os03g0178100 & OSHMAB & 12.85 & 11.85 & 1.08 \\
\hline BGIOSGA020720 & Os06g0665800 & OsHMA9 & 74.27 & 68.57 & 1.08 \\
\hline \multicolumn{6}{|c|}{ OsABC transporter family } \\
\hline BGIOSGA001233 & Os01g0609300 & OsABCG36/OsPDR9 & 0.34 & 2.70 & 0.13 \\
\hline BGIOSGA004262 & Os01g0696600 & OsABCB4 & 11.83 & 26.58 & 0.45 \\
\hline BGIOSGA028618 & Os08g0398300 & OsABCA7 & 3.15 & 7.53 & 0.42 \\
\hline BGIOSGA015573 & Os04g0209200 & OsABCC14 & 2.12 & 6.01 & 0.35 \\
\hline
\end{tabular}

roots under Cd exposure compared with the other genes. OsNRAMP1 was involved in uptake and accumulation of Fe and $\mathrm{Cd}$ in rice. Over-expression of OsNRAMP1 in rice enhanced $\mathrm{Cd}$ accumulation in the leaves [15]. In this study, OsNRAMP1 expression was markedly decreased by 3.1 -fold in $l c d 1$ root compared with WT root at $6 \mathrm{~h}$ after
$\mathrm{Cd}$ exposure, indicating that the low $\mathrm{Cd}$ uptake and accumulation in $l c d 1$ root could be partly explained by the decreased expression of OsNRAMP1. Moreover, OsHMA3 has been identified as major regulator for xylem $\mathrm{Cd}$ transport in rice. OsHMA3 participates in the sequestration of $\mathrm{Cd}$ into vacuoles and affects root-to-shoot $\mathrm{Cd}$ 
translocation in rice. Overexpression of OsHMA3 enhanced $\mathrm{Cd}$ tolerance in rice [19], while loss-of-function allele of OsHMA3 resulted in high $\mathrm{Cd}$ accumulation in rice shoots and grain in some Indica rice cultivars [38]. In this study, OsHMA3 protein coding sequence in indica rice 9311 was identical to the type V alleles of OsHMA3 as reported by Yan et al. [38], which was proved to be functional by heterologous expression in yeast. There was no SNP and InDel detected in lcd 1 OsHMA3 compared with WT, indicating no loss of function mutation of OsHMA3 in the $l c d 1$ mutant. Furthermore, OsHMA3 expression was increased by 1.3 -fold in $l c d 1$ root compared with WT root at $6 \mathrm{~h}$ after $\mathrm{Cd}$ exposure, suggesting that increased OsHMA3 expression probably adds to the effect of OsNRAMP5 mutation to account for the significant decreases in $\mathrm{Cd}$ accumulation in rice plant and grain of the $l c d 1$ mutant. In addition to OsHMA3, some PDR-type ABC transporters have been found to participate in Cd detoxification in plants. AtPDR8 conferred Cd tolerance in Arabidopsis by pumping $\mathrm{Cd}^{2+}$ out across the plasma membrane of root epidermal cells [17]. In this study, the expressions of four $\mathrm{ABC}$ transporter encoding genes were all significantly down-regulated in $l c d 1$ root compared with WT root under Cd exposure, of which OsABCG36/OsPDR9 showed a 7.9-fold decreased expression. This might be due to that the lower $\mathrm{Cd}$ uptake and intracellular $\mathrm{Cd}$ level in the root cell of $l c d 1$ caused weaker induction of OsABCG36/OsPDR9 expression in lcd1 root compared with in WT root. Actually, previous studies have demonstrated that OsPDR9 was differentially induced by $\mathrm{Cd}$ stress. Moons [39] suggested that OsPDR9 was rapidly induced by $\mathrm{Cd}$ stress in roots of rice seedlings. Tan et al. [18] also found that OsABCG36/OsPDR9 expression was remarkably induced by $\mathrm{Cd}$ in rice roots, which is basically consistent with our results, indicating the potential role of $\mathrm{ABC}$ transporters in regulating $\mathrm{Cd}$ tolerance in rice plants.

\section{Additional files}

Additional file 1: Table S1. The primer sequences for quantitative realtime RT-PCR (DOCX $19 \mathrm{~kb})$

Additional file 2: Table S2. The PCR amplification efficiency for each primer pair (DOCX $19 \mathrm{~kb}$ )

Additional file 3: Table S3. Comparison of the main agronomic traits between $/ c d 1$ and WT plants (DOCX $15 \mathrm{~kb}$ )

Additional file 4: Figure S1. Metal concentrations in $/ c d 1$ and WT grains grown on $\mathrm{Cd}$-contaminated fields. (TIF $158 \mathrm{~kb}$ )

Additional file 5: Figure S2. Metal concentrations in shoots and roots of ICdl and WT seedlings exposed to $5 \mu \mathrm{M} \mathrm{CdCl}$. (TIF $86 \mathrm{~kb}$ )

Additional file 6: Figure S3. $\Delta$ SNP-index plots of two pools on all 12 chromosomes generated by MutMap analysis. (TIF $494 \mathrm{~kb}$ )

Additional file 7: The list of detected genes from RNA-Seq for $|c d|$ and WT under Cd exposure. co_exp: genes with the common expression for Icd1 and WT; specific_exp: genes specific for Icd1 and WT. (XLS 3494 kb)

\section{Abbreviations}

ABC: ATP-binding cassette transporter; DEGs: differential expressed genes; EMS: ethyl methanesulfonate; GO: gene ontology; HMA: heavy-metal ATPase; NRAMP: natural resistance-associated macrophage protein; PC: phytochelatin; QTL: quantitative trait locus; RNA-seq: RNA sequencing; ZIP: zinc-regulated transporter/iron-regulated transporter-like protein

\section{Acknowledgements}

We would like to thank Pro. Weixing Zhang (China National Rice Research Institute, Hangzhou, China) for proving the technical assistance.

\section{Authors' contributions}

ZC designed the research, performed the experiments and drafted the manuscript. $X L$ and $Y Y$ analyzed the data and helped in the preparation lof various parts of the manuscript. MG and PX provided support with instrumental analysis. MC supervised the study and contributed in writing the manuscript. All authors read and approved the final manuscript.

\section{Funding}

This research was supported by the National Natural Science Foundation of China (No. 31701408, No. 31801304), the Zhejiang Provincial Natural Science Foundation of China (No. LQ17C130002) and the earmarked fund for China Agriculture Research System (CARS-01-47). These funding bodies played no role in the design of the study and collection, analysis, and interpretation of data and in writing the manuscript.

\section{Availability of data and materials}

All the data is contained within the manuscript.

Ethics approval and consent to participate Not applicable.

\section{Consent for publication}

Not applicable.

\section{Competing interests}

The authors declare that they have no competing interests.

Received: 13 March 2019 Accepted: 3 June 2019

Published online: 11 June 2019

\section{References}

1. Nawrot TS, Staessen JA, Roels HA, Munters E, Cuypers A, Richart T, Ruttens A, Smeets $\mathrm{K}$, Clijsters $\mathrm{H}$, Vangronsveld J. Cadmium exposure in the population: from health risks to strategies of prevention. Biometals. 2010; 23(5):769-82.

2. Arunakumara KKIU, Walpola BC, Yoon $\mathrm{MH}$. Current status of heavy metal contamination in Asia's rice lands. Rev Environ Sci Bio. 2013;12(4):355-77.

3. Wang L, Cui X, Cheng H, Chen F, Wang J, Zhao X, Lin C, Pu X. A review of soil cadmium contamination in China including a health risk assessment. Environ Sci Pollut R. 2015;22(21):16441-52.

4. Ke S, Cheng XY, Zhang N, Hu HG, Yan Q, Hou LL, Sun X, Chen ZN. Cadmium contamination of rice from various polluted areas of China and its potential risks to human health. Environ Monit Assess. 2015;187(7):408.

5. Uraguchi S, Fujiwara T. Rice breaks ground for cadmium-free cereals. Curr Opin Plant Biol. 2013;16(3):328-34.

6. Clemens S, Aarts MG, Thomine S, Verbruggen N. Plant science: the key to preventing slow cadmium poisoning. Trends Plant Sci. 2013;18(2):92-9.

7. Clemens S, Ma JF. Toxic heavy metal and metalloid accumulation in crop plants and foods. Annu Rev Plant Biol. 2016;67:489-512.

8. Ishikawa S, Ae N, Yano M. Chromosomal regions with quantitative trait loci controlling cadmium concentration in brown rice (Oryza sativa). New Phytol. 2005;168(2):345-50.

9. Abe T, Nonoue Y, Ono N, Omoteno M, Kuramata M, Fukuoka S, Yamamoto $\mathrm{T}$, Yano M, Ishikawa S. Detection of QTLs to reduce cadmium content in rice grains using LAC23/Koshihikari chromosome segment substitution lines. Breeding Sci. 2013;63(3):284-91.

10. Ishikawa S, Abe T, Kuramata M, Yamaguchi M, Ando T, Yamamoto T, Yano M. A major quantitative trait locus for increasing cadmium-specific concentration in rice grain is located on the short arm of chromosome 7. J Exp Bot. 2009;61(3):923-34 
11. Tezuka K, Miyadate H, Katou K, Kodama I, Matsumoto S, Kawamoto T, Masaki S, Satoh H, Yamaguchi M, Sakurai K, Takahashi H, Satoh-Nagasawa N, Watanabe A, Fujimura T, Akagi H. A single recessive gene controls cadmium translocation in the cadmium hyperaccumulating rice cultivar Cho-Ko-koku. Theor Appl Genet. 2010;120(6):1175-82.

12. Sasaki A, Yamaji N, Ma JF. Transporters involved in mineral nutrient uptake in rice. J Exp Bot. 2016;67(12):3645-53.

13. Ishikawa S, Ishimaru Y, Igura M, Kuramata M, Abe T, Senoura T, Hase Y, Arao T, Nishizawa NK, Nakanishi H. Ion-beam irradiation, gene identification, and marker-assisted breeding in the development of low-cadmium rice. P Natl Acad Sci USA. 2012;109(47):19166-71.

14. Sasaki A, Yamaji N, Yokosho K, Ma JF. Nramp5 is a major transporter responsible for manganese and cadmium uptake in rice. Plant Cell. 2012; 24(5):2155-67.

15. Takahashi R, Ishimaru Y, Senoura T, Shimo H, Ishikawa S, Arao T, Nakanishi H, Nishizawa NK. The OsNRAMP1 iron transporter is involved in $\mathrm{cd}$ accumulation in rice. J Exp Bot. 2011;62(14):4843-50.

16. Nakanishi H, Ogawa I, Ishimaru Y, Mori S, Nishizawa NK. Iron deficiency enhances cadmium uptake and translocation mediated by the $\mathrm{Fe}^{2+}$ transporters OsIRT1 and OsIRT2 in rice. Soil Sci Plant Nutr. 2006;52(4):464-9.

17. Kim DY, Bovet L, Maeshima M, Martinoia E, Lee $Y$. The ABC transporter AtPDR8 is a cadmium extrusion pump conferring heavy metal resistance. Plant J. 2007;50(2):207-18.

18. Tan M, Cheng D, Yang Y, Zhang G, Qin M, Chen J, Chen Y, Jiang M. Coexpression network analysis of the transcriptomes of rice roots exposed to various cadmium stresses reveals universal cadmium-responsive genes. BMC Plant Biol. 2017;17(1):194

19. Sasaki A, Yamaji N, Ma JF. Overexpression of OsHMA3 enhances cd tolerance and expression of Zn transporter genes in rice. J Exp Bot. 2014; 65(20):6013-21.

20. Ding Y, Chen Z, Zhu C. Microarray-based analysis of cadmium-responsive microRNAs in rice (Oryza sativa). J Exp Bot. 2011;62(10):3563-73.

21. Lopes MS, Iglesia-Turino S, Cabrera-Bosquet L, Serret MD, Bort J, Febrero A, Araus JL. Molecular and physiological mechanisms associated with root exposure to mercury in barley. Metallomics. 2013;5(9):1305-15.

22. Lin CY, Trinh NN, Fu SF, Hsiung YC, Chia LC, Lin CW, Huang HJ. Comparison of early transcriptome responses to copper and cadmium in rice roots. Plant Mol Biol. 2013;81(4-5):507-22

23. Liu Q, Zhang H. Molecular identification and analysis of arsenite stressresponsive miRNAs in rice. J Agr Food Chem. 2012;60(26):6524-36.

24. He F, Liu Q, Zheng L, Cui Y, Shen Z, Zheng L. RNA-Seq analysis of rice roots reveals the involvement of post-transcriptional regulation in response to cadmium stress. Front Plant Sci. 2015;6:1136.

25. Chen L, Shi S, Jiang N, Khanzada H, Wassan GM, Zhu C, Peng X, Xu J, Chen Y, Yu Q, He X. Genome-wide analysis of long non-coding RNAs affecting roots development at an early stage in the rice response to cadmium stress. BMC Genomics. 2018;19(1):460.

26. Yoshida S, Forno DA, Cock JH, Gomez KA. Laboratory manual for physiological studies of rice. 3rd ed. Manila: International Rice Research Institute; 1976

27. Uraguchi S, Mori S, Kuramata M, Kawasaki A, Arao T, Ishikawa S. Root-to-shoot cd translocation via the xylem is the major process determining shoot and grain cadmium accumulation in rice. J Exp Bot. 2009;60(9):2677-88.

28. Cao ZZ, Mou RX, Cao ZY, Lin XY, Xu P, Chen ZJ, Zhu ZW, Chen MX. Nickel in milled rice (Oryza sativa L.) from the three main rice-producing regions in China. Food Addit Contam Part B. 2017;10(1):69-77.

29. Bustin SA, Benes V, Garson JA, Hellemans J, Huggett J, Kubista M, Mueller R, Nolan T, Pfaffl MW, Shipley GL, Vandesompele J, Wittwer CT. The MIQE guidelines: minimum information for publication of quantitative real-time PCR experiments. Clin Chem. 2009;55(4):611.

30. Ashrafzadeh S, Leung DW. Development of cadmium-safe crop cultivars: a mini review. J Crop Improv. 2016;30(2):107-17.

31. Takagi H, Tamiru M, Abe A, Yoshida K, Uemura A, Yaegashi H, Obara T, Oikawa K, Utsushi H, Kanzaki E, Mitsuoka C, Natsume S, Kosugi S, Kanzaki H, Matsumura H, Urasaki N, Kamoun S, Terauchi R. MutMap accelerates breeding of a salt-tolerant rice cultivar. Nat Biotechnol. 2015;33(5):445.

32. Abe A, Kosugi S, Yoshida K, Natsume S, Takagi H, Kanzaki H, Matsumura H, Yoshida K, Mitsuoka C, Tamiru M, Innan H, Cano L, Kamoun S, Terauchi R. Genome sequencing reveals agronomically important loci in rice using MutMap. Nat Biotechnol. 2012;30(2):174
33. Wang $H$, Zhang $Y X$, Sun LP, Xu P, Tu RR, Meng S, Wu WX, Anis GB, Hussain $\mathrm{K}$, Riaz A, Chen DB, Cao LY, Cheng SH, Shen XH. WB1, a regulator of endosperm development in Rice, is identified by a modified MutMap method. Int J Mol Sci. 2018;19(8):2159.

34. Tang L, Mao BG, Li YK, Lv QM, Zhang LP, Chen CY, He HJ, Wang WP, Zeng XF, Shao Y, Pan YL, Hu YY, Peng Y, Fu XQ, Li HQ, Xia ST, Zhao BR. Knockout of OsNramp5 using the CRISPR/Cas9 system produces low cd-accumulating indica rice without compromising yield. Sci Rep. 2017;7(1):14438.

35. Peng H, He X, Gao J, Ma H, Zhang Z, Shen Y, Pan G, Lin H. Transcriptomic changes during maize roots development responsive to cadmium (cd) pollution using comparative RNAseq-based approach. Biochem Bioph Res Co. 2015;464(4):1040-7.

36. Kintlová M, Blavet N, Cegan R, Hobza R. Transcriptome of barley under three different heavy metal stress reaction. Genomics Data. 2017;13:15-7.

37. Astudillo-Reyes C, Fernandez AC, Cichy KA. Transcriptome characterization of developing bean (Phaseolus vulgaris L.) pods from two genotypes with contrasting seed zinc concentrations. PLoS One. 2015;10(9):e0137157.

38. Yan JL, Wang PT, Wang P, Yang M, Lian XM, Tang Z, Huang CF, Salt DE, Zhao FJ. A loss-of-function allele of OsHMA3 associated with high cadmium accumulation in shoots and grain of japonica rice cultivars. Plant Cell Environ. 2016;39(9):1941-54.

39. Moons A. Ospdr9, which encodes a PDR-type ABC transporter, is induced by heavy metals, hypoxic stress and redox perturbations in rice roots 1. FEBS Lett. 2003;553(3):370-6.

\section{Publisher's Note}

Springer Nature remains neutral with regard to jurisdictional claims in published maps and institutional affiliations.

\section{Ready to submit your research? Choose BMC and benefit from:}

- fast, convenient online submission

- thorough peer review by experienced researchers in your field

- rapid publication on acceptance

- support for research data, including large and complex data types

- gold Open Access which fosters wider collaboration and increased citations

- maximum visibility for your research: over $100 \mathrm{M}$ website views per year

At BMC, research is always in progress.

Learn more biomedcentral.com/submissions 